\title{
An Optimized Chemical and Mechanical Engineering Design of an Ammonia Reactor
}

\author{
Ibrahim Mohamed Mahmoud Aboelkheir \\ Aboelkheir Investments, Dubai, United Arab Emirates \\ aboelcare@gmail.com \\ DOI: 10.47760/cognizance.2022.v02i01.002
}

\begin{abstract}
Design of an ammonia reactor was conceived as part of a series of item designs for an ammonia plant in Cyprus. The Chemical and Mechanical aspects of the design were considered. Optimization of these designs was studied, worked on, \& discussed. The safety, environmental and legal regulations of relevant reactor regulations were followed in the design concerned.

Keywords- Chemical Design, Chemical Engineering, Ammonia Reactor, Optimized Design
\end{abstract}

\section{INTRODUCTION}

There was requested the design of an ammonia plant, by which this paper is concerned with the chemical \& mechanical engineering design of the ammonia reactor of the plant.

Basis specifications \& restrictions by the requesting entity for the chemical \& mechanical engineering design of the catalytic ammonia reactor are (Patel, 2020):

$>$ The reactor is to produce 85 tons per day of ammonia.

$>$ That the reactor is to be is to be operational for 330 days per year with a shut down for annual maintenance.

$>$ Process safety must be considered at all stages of the reactor design.

$>$ Proper concern for the environment must also be given throughout the design of the reactor.

In order to explore other design restrictions \& to design an optimal reactor, commentary on a range of literature pertaining to the chemical engineering design of an ammonia reactor is needed.

\section{CHAPTER 1}

\section{Chemical Engineering Design of an Ammonia Reactor}

\section{Section 1: Chemical Engineering Design Methodology OUtline}

A clear approach to the chemical engineering design methodology is to be reviewed to demonstrate the reasoning behind the parameters \& aspects of the design this paper produces.

According to Coulson and Richardson's Chemical Engineering Design, (Coulson, et al., 2005) the methodology of the design is initiated by a specific objective in mind. This chapter is concerned with the optimisation of an 85 ton/day ammonia reactor, by which the reactor is further constrained by the pressure \& temperature from the overall plant material balance design. Attempts at optimising these values failed due to their previous optimisation. Using these constraints \& the degrees of freedom, choice of process conditions, materials, equipment \& parameters will be elaborated on.

Literature discussing the choice of what type of reactor to design is to be reviewed.

\subsubsection{The Initial design considerations of the Cyprus Ammonia Reactor in the paper titled "Liquid Ammonium Plant"}

The ammonia reactor this paper is providing the chemical engineering design of is the item R-5 in the PFD of the ammonia plant designed in the paper "Liquid Ammonium Plant" (Abo Elkheir, et al., 2021). The reactor loop of the R-5 can be seen on the PFD in Figure 1. 


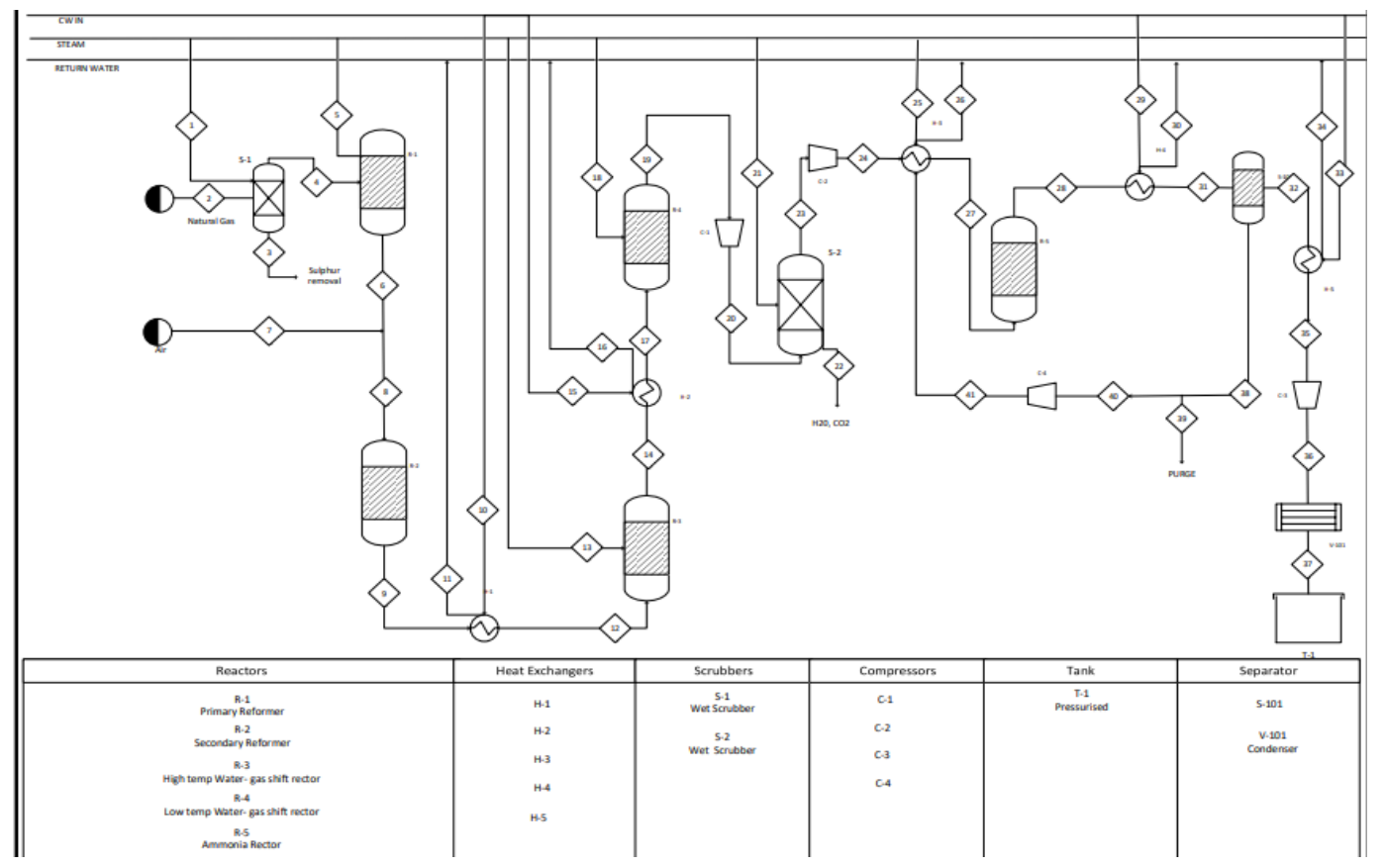

Figure 1. PFD of the Cyrpus Ammonia Plant (Abo Elkheir, et al., 2021)

The paper "Liquid Ammonium Plant" (Abo Elkheir, et al., 2021) provides the material \& mass flow parameters for the reactor design. The theory behind these calculations can be found in the Appendices to the Chemical Engineering Design.

A mistake in that paper relevant to the chemical engineering design of the reactor is use of keq in place of kP without suitable conversion. There are two chemical engineering designs in this paper, each, of which, remedy's this predicament by producing KP with a different method.

To start with the chemical engineering design, an examination to a design paper is needed, of which to compare latterly with the designs of this R-5 reactor based on equations from design books (Coulson, et al., 2005) (Levenspiel, 1999) (Rosen, 2014).

\subsubsection{The Chemical Engineering Design of an Ammonia Reactor in the paper titled "2500 MTPD OF AMMONIA FROM NAPHTHA"}

In this section, the piece of literature titled "2500 MTPD OF AMMONIA FROM NAPHTHA (Abbas \& G, 2015)" will be displayed and reviewed where relevant to the consequent chemical engineering design of an optimized ammonia reactor achieved in this paper. This data is to be compared with the R-5 Reactor chemical engineering design.

\subsubsection{Chemical Engineering Design calculations}

The calculations can be found in the Appendices to the Chemical Engineering Design.

The results found in the appendix demonstrate that the volume of the catalyst was found using the flowrates. This is faulty as the book, Chemical Reaction Engineering, clearly specifies that the volumes are derived from reaction kinetics pertaining to relevant processes \& reactors to the ammonia reactor design (Levenspiel, 1999).

\subsubsection{Dynamic Model of an Ammonia Synthesis Reactor based on Open Information}

"Dynamic Model of an Ammonia Synthesis Reactor based on Open Information" (Glemmestad, et al., 2018) provides material \& mass balance considerations that overlay \& correct the calculations demonstrated for the ammonia plant that this paper is basing the material \& mass calculations on (Abo Elkheir, et al., 2021).

\section{SECTION 2: COMPLETE CHEMICAL ENGINEERING DESIGN OF THE REACTOR}

\subsubsection{Specifications of the ammonia reactor}

The Design's Framework

The major constraints on the design are the design temperature, pressure, chosen catalyst with its density and particle size, initial flow rates, kinetic and physical properties of the components. These will be used in the design stage to design and assess the reactor volume and catalyst volume designs. 


\subsubsection{Statement of duty}

In the presence of an iron catalyst, a reactor's function is to convert synthesis gas to ammonia. Nitrogen and hydrogen are used in the synthesis gas. (Abbas \& G, 2015)

The following streams $27 \& 28$ were calculated in the previous paper \& corrected to provide insight on the design.

Table 1

\begin{tabular}{|l|l|}
\hline P27 & $\begin{array}{l}\text { P28 } \text { (Reactor } \\
\text { Output) }\end{array}$ \\
\hline $\mathbf{2 8 5 . 1 5 4 4 6 2}$ & $\mathbf{2 8 5 . 1 5 4 4 6 1 6}$ \\
\hline $\mathbf{0 . 0 0 6 1 6 8 9 1}$ & $\mathbf{0 . 0 0 6 1 6 8 9 1 1}$ \\
\hline 10.0812183 & $\mathbf{1 0 . 0 8 1 2 1 8 3 4}$ \\
\hline 4360.73599 & $\mathbf{4 0 8 2 . 2 8 8 0 6}$ \\
\hline 14.5724416 & $\mathbf{5 7 1 . 4 6 8 2 9 9 1}$ \\
\hline $\mathbf{3 0 . 0 9 1 4 1 3 3}$ & $\mathbf{3 0 . 0 9 1 4 1 3 3 2}$ \\
\hline $\mathbf{0 . 1 2 4 5 1 3 6 4}$ & $\mathbf{0 . 1 2 4 5 1 3 6 4}$ \\
\hline 16.7418212 & $\mathbf{1 6 . 7 4 1 8 2 1 2 5}$ \\
\hline $\mathbf{9 0 8 . 3 8 7 0 9 4}$ & $\mathbf{7 3 . 0 4 3 3 0 8 3 1}$ \\
\hline $\mathbf{5 6 2 5 . 8 9 5 1 2}$ & $\mathbf{5 0 6 8 . 9 9 9 2 6 5}$ \\
\hline
\end{tabular}

The reactor output is to produce the amount of ammonia necessary for the loop to provide 85 tonnes of ammonia per day. (Abo Elkheir, et al., 2021)

Table 2

\begin{tabular}{|l|l|}
\hline Total Production $(\mathbf{K g})$ & 85000 \\
\hline Reactor Production $(\mathbf{k g}$ (hr-1) & 130332.1 \\
\hline Loop Production $(\mathbf{K g}$ *hr-1) & 9875.8 \\
\hline Work hours per day & 9.01 \\
\hline NH3 mole fraction & $97.05 \%$ \\
\hline
\end{tabular}

Reflux is such that ammonia exits at $97 \%$

The purge ratio is 0.15 where the $\mathrm{CH} 4$

Table 3

\begin{tabular}{|l|l|}
\hline Components & $\begin{array}{l}\text { Purge Stream } \\
\left(\text { kg*hr-1 }^{*}\right.\end{array}$ \\
\hline CH4 & 681.80 \\
\hline H2S & 0.03 \\
\hline O2 & 48.21 \\
\hline N2 & 17080.96 \\
\hline NH3 & 43.72 \\
\hline H2O & 27.12 \\
\hline CO & 17080.96 \\
\hline CO2 & 3757.72 \\
\hline H2 & 21.76 \\
\hline Total & 38742.28 \\
\hline
\end{tabular}


Waste exiting the R-5 reactor in stream 28 cannot constitute the final product. Previously deratioed components such as Co \& $\mathrm{CO} 2$ increase in their mole fraction due to the ammonia loop. $\mathrm{CH} 4$ on the other hand, wasn't separated nor reacted considerably to reduce its fraction, but rather it increases in the loop as well. This is a direct result to the process of which the reactor R-5 is part of, as the design fails to produce or consider solutions such as reacting these components. As such, in the preceding design paper, Liquid Ammonium Plant, (Abo Elkheir, et al., 2021) the purge stream was designed to reduce the ratio of $\mathrm{CH} 4, \mathrm{CO} \& \mathrm{CO}$. These compounds that exit the R-5 reactor rise a harm to the environment by its byproduct purge. The purge stream shows potential for rerouting $\mathrm{CO} \& \mathrm{CO} 2$ back into the earlier streams in the plant and to react with $\mathrm{SH} 2$ to produce useful compounds for the plant. Thus the environmental harm of the R-5 reactor is decreased. These compounds, along with $\mathrm{CH} 4$ also show potential for being sold in the market.

\subsubsection{A preliminary recommendation as to the type of equipment to be employed}

\subsubsection{Reactor Type}

Chemical reactors are classified into two ways, according to type of operation, according to design feature (Abbas \& G, 2015):

1) Batch reactor

2) Continuous reactor

A continuous process is chosen as it is more suitable for high scale productions with a lower production cost. The lower flexibility of the reactor is not as much needed to raise issue for this reactor design (Coulson, et al., 2005).

The reaction is heterogenous exothermic as the ammonia homogenous reaction is too ineffective (Levenspiel, 1999).

The reactor type to choose is between two feasible choices, packed bed reactors \& fluidized bed reactors. The former is chosen due to:

\subsubsection{Justification}

1) Widespread application

2) Lower operating costs

3) Greater control over product quality

4) Improved temperature control (Abbas \& G, 2015)

5) Continuous

6) Production rate greater than $5 * 10^{\wedge} 6 \mathrm{~kg} / \mathrm{h}$

7) Single product

8) No severe fouling

9) Good catalyst life

10) Proven processes design

11) Established market

\subsubsection{An estimate of any services required}

\section{Services Offered}

On-site services include steam, cooling water, process water, electricity, compressed and instrument air (Patel, 2020).

Services Required:

1) cooling water for the output

2) electricity for the heating and pumps

3) compressed air for pumping

\subsubsection{Recommendations regarding materials of construction.}

Table 4

\begin{tabular}{|l|}
\hline Stainless steel 304 \\
\hline Stainless steel 316 \\
\hline Stainless steel 321 \\
\hline Low alloy steel (Ni, Cr, Mo, V) \\
\hline
\end{tabular}

These four types of steel are recommended to be the material that makes the vessel and the flanges.

They are by the ASME design standards which are the chosen standard for the R-5 reactor as they are accepted in Cyprus. Stainless steel \& low alloy steel variants are the material range to examine as they are widely employed in the construction of Ammonia reactors, flanges \& pipes in the industry. (Abbas \& G, 2015) (Choudhury, et al., 2020). Their suitability for pressure vessels is proven by their use in standards such as ASME \& BS. 
These materials have:

1) Strength tensile strength

2) Stiffness elastic modulus (Young's modulus)

3) Toughness fracture resistance

4) Hardness wear resistance

5) Fatigue resistance

6) Creep resistance (Coulson, et al., 2005)

They age well with high temperatures as opposed to cold temperatures, the first of which is the temperature range for the ammonia reaction. They are also easy to fabric, form, weld \& cast. The costing is feasible, and the sizes are all covered by ASME.

\subsubsection{Designs}

\subsubsection{The First Chemical Engineering Design per the First Set of Parameters}

\subsubsection{Assumptions}

- The model is one-dimensional, with temperature and molar gradients varying only axially.

- $\quad$ For the system, the Temkin-Pyzhev reaction rate expression is valid (Murase et al., 1970; Morud and Skogestad, 1998; Froment et al., 2010).

- The compartments of the discretized reactor volume are well mixed.

- The system contains no heat or mass diffusion.

- Individual gases and gas mixtures exhibit ideal gas behavior.

- The activity of the catalyst is consistent throughout the reactor.

- The coefficient of heat transfer, the heat of reaction, and the heat capacities are constants. (Glemmestad, et al., 2018)

- The reactor's pressure is precisely controlled.

- The reactor arrives to steady state at $450{ }^{\circ} \mathrm{C}$

\subsubsection{Methodology}

The main parameter to determine for the chemical engineering design is the volume of the reactor.

\subsubsection{The Volume of the Reactor}

It, along with other parameters, is utilised to optimise the reactor by increasing revenue $\&$ decreasing cost. The volume of the reactor is determined as:

$$
\mathrm{V}_{\text {reactor }}=\frac{\mathrm{V}_{\text {catalyst }}}{1-\varepsilon}
$$

This former equation is derived from the latter:

$$
\varepsilon=\frac{\mathrm{V}_{\text {reactor }}-\mathrm{V}_{\text {catalyst }}}{\mathrm{V}_{\text {reactor }}}
$$

(Levenspiel, 1999)

The volume of the catalyst is such as:

$$
\mathrm{V}_{\text {catalyst }}=\frac{\mathrm{W}_{\text {catalyst }}}{\rho_{\text {catalyst }}}
$$

(Levenspiel, 1999)

Whereby the Mass of the catalyst, $\mathrm{W}_{\text {catalyst }}$, is derived as:

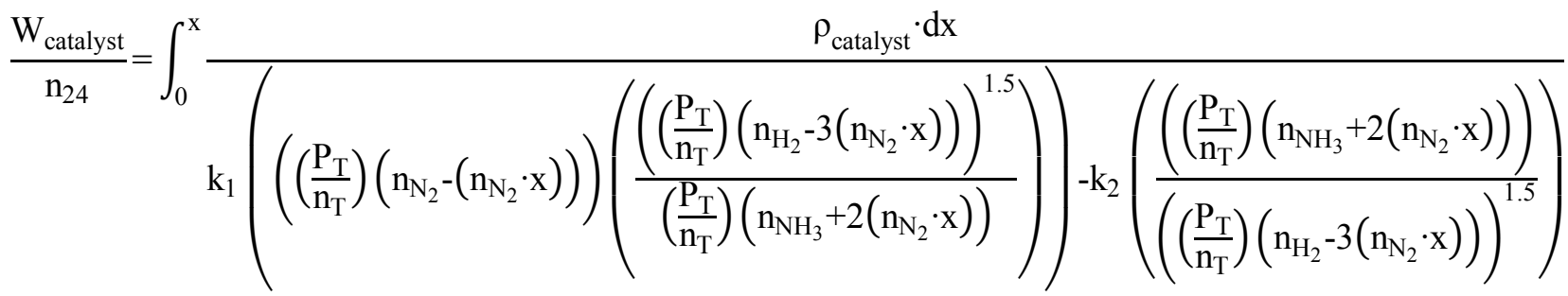


This is an integrated version of the Temkin-Pyzhev equation (Murase, et al., 1970) (Morud \& Skogestad, n.d.) (Glemmestad, et al., 2018) (Levenspiel, 1999).

Where k1 \& k2, based upon the Gibbs free energy approach, are:

$$
\mathrm{k}_{1}=\mathrm{k}_{0,1} \mathrm{e}^{-\frac{\mathrm{E}_{1}}{\mathrm{R}_{\mathrm{cat}} \mathrm{T}_{28}}}
$$

(Froment, et al., n.d.) (Levenspiel, 1999)

$$
\mathrm{k}_{1}=\mathrm{k}_{0,2} \mathrm{e}^{-\frac{\mathrm{E}_{2}}{\mathrm{R}_{\mathrm{cat}} \mathrm{T}_{28}}}
$$

(Froment, et al., n.d.) (Levenspiel, 1999)

The filled equations are in the appendix.

Whereas the reaction pressure is a constraint so a constant, and the density of the catalyst is a chosen value, the input stream of the reactor $\mathrm{n} 27$ is determinable by the loop entry stream $\mathrm{n} 24$, the extent of reaction calculations that determine the streams in the paper "Liquid Ammonium Plant" (Abo Elkheir, et al., 2021) are revisited with the Gillespie \& Beattie correlation for the equilibrium pressure constant. This changes the loop calculations slightly to suit this design. The Gillespie \& Beattie correlation is found as:

$$
\mathrm{k}_{\mathrm{p}}=\frac{\mathrm{k}_{1}}{\mathrm{k}_{2}}
$$

(Gillespie \& Beattie, 1930)

Using $\mathrm{kp}$, the extent of reaction is calculated, by which the flowrates of the streams are determined.

Under the constraint of the temperature at 450 Celsius, the maximum conversion is determined as:

$$
\mathrm{x}=\left(\frac{\mathrm{n}_{27, \mathrm{~N}_{2}}-\mathrm{n}_{28, \mathrm{~N}_{2}}}{\mathrm{n}_{27, \mathrm{~N}_{2}}}\right)
$$

This constraint, along with the reaction pressure, is subjected externally by the paper "Liquid Ammonium Plant" (Abo Elkheir, et al., 2021), as the optimum balance between temperature \& pressure was found as such. Yet, these two values are internally constraint as well, as the optimization of the mechanical design in CHAPTER2, SECTION 4: SELECTED OPTIMIZED DESIGN OF THE R-5 REACTOR, found them the most suitable for safety, the environment, and most importantly, the small sizing of the reactor and catalyst mass.

The equation of the weight of the catalyst is thus integrated between $0 \&$ the maximum conversion to produce, after steps of calculations, the volume of the reactor.

If more degrees of freedom where available, the second method would be utilized:

\subsubsection{Second method}

Where the reaction temperature, $\mathrm{T}$, is not known, a high conversion value, 0.9999 , is inputted through the following equation:

$$
\mathrm{k}_{\mathrm{eq}}=\left(\frac{\left(\mathrm{n}_{\mathrm{NH}_{3}}+2\left(\mathrm{n}_{\mathrm{N}_{2}} \cdot \mathrm{x}\right)\right)^{2}}{\left(\mathrm{n}_{\mathrm{H}_{2}}-3\left(\mathrm{n}_{\mathrm{N}_{2}} \cdot \mathrm{x}\right)\right)^{3}\left(\mathrm{n}_{\mathrm{N}_{2}}-\left(\mathrm{n}_{\mathrm{N}_{2}} \cdot \mathrm{x}\right)\right)}\right)
$$

(Levenspiel, 1999)

Where,

$$
\mathrm{k}_{\mathrm{eq}}=\log \left((-2.69112 \cdot \log \mathrm{T})-\left(5.051925 \cdot\left(10^{-5}\right) * \mathrm{~T}\right)+\left(1.848863 *\left(10^{-7}\right) \cdot \mathrm{T}^{2}\right)+\left(\frac{2001.6}{\mathrm{~T}}\right)+2.689\right)
$$

(Glemmestad, et al., 2018) 
The slope of the relationship between conversion \& the temperature of the reaction is used to determine the rate of the equation at multiple points.

Approximation of the integration of the Mass of the catalyst is then used to determine the volume of the reactor through some calculations (Levenspiel, 1999). This is not possible due to the temperature constraint.

Calculation of the pressure drop is the Second most important parameter in the chemical engineering design of the reactor.

\subsubsection{For pressure drop}

Pressure drop is as:

$$
\text { pressure drop }=\mathrm{P}_{27}-\mathrm{P}_{28}
$$

Where,

$$
\mathrm{P}_{28}=\sqrt{\mathrm{P}_{27}{ }^{2}-2 \mathrm{~L}_{\text {cylinder }} \cdot\left((1-\varepsilon) \cdot \frac{\mathrm{G}}{\mathrm{D}_{\mathrm{P}} \cdot \rho_{\text {catalyst }} \cdot \mathrm{g} \cdot\left((\varepsilon)^{3}\right)}\right)\left(\left(\frac{150 \cdot(1-(\varepsilon)) \cdot \mu}{\mathrm{D}_{\mathrm{P}}}\right)+((1.75 \cdot \mathrm{G}))\right)\left(\left(\mathrm{n}_{27, \mathrm{~T}} \cdot \frac{\mathrm{P}_{27}}{\mathrm{n}_{28, \mathrm{~T}}}\right) \frac{\mathrm{T}_{28}}{\mathrm{~T}_{27}}\right)}
$$

Where, Lcylinder, is found using the heuristic relationship:

$$
\mathrm{L}=2.5 \mathrm{D}
$$

And D determined by:

$$
\mathrm{D}=\mathrm{V}_{\text {reactor }}\left(\left(\frac{4}{\pi(2.5)}\right)\right)^{\frac{1}{3}}
$$

The former equation is derived from the latter:

$$
\frac{\mathrm{dP}}{\mathrm{dz}}=-\left((1-\varepsilon) \cdot \frac{\mathrm{G}}{\mathrm{D}_{\mathrm{P}} \cdot \rho_{\text {catalyst }} \cdot \mathrm{g} \cdot\left((\varepsilon)^{3}\right)}\right)\left(\left(\frac{150 \cdot(1-(\varepsilon)) \cdot \mu}{\mathrm{D}_{\mathrm{P}}}\right)+((1.75 \cdot \mathrm{G}))\right)\left(\left(\mathrm{n}_{27, \mathrm{~T}} \cdot \frac{\mathrm{P}_{27}}{\mathrm{n}_{28, \mathrm{~T}}}\right) \frac{\mathrm{T}_{28}}{\mathrm{~T}_{27}}\right)
$$

(Rosen, 2014)

And,

$$
\frac{\mathrm{dP}}{\mathrm{dz}}=-\beta\left(\left(\mathrm{n}_{27, \mathrm{~T}} \cdot \frac{\mathrm{P}_{27}}{\mathrm{n}_{28, \mathrm{~T}}}\right) \frac{\mathrm{T}_{28}}{\mathrm{~T}_{27}}\right)
$$

(Rosen, 2014)

And,

$$
-\beta=-\left((1-\varepsilon) \cdot \frac{G}{D_{P} \cdot \rho_{\text {catalyst }} \cdot g \cdot\left((\varepsilon)^{3}\right)}\right)\left(\left(\frac{150 \cdot(1-(\varepsilon)) \cdot \mu}{D_{P}}\right)+((1.75 \cdot G))\right)
$$

(Rosen, 2014) 
Whereby, T27 is defined for an adiabatic exothermic reactor as:

$$
\mathrm{T}_{27}=\mathrm{T}_{28^{-}}\left(-\Delta \mathrm{H}_{\mathrm{r}} \cdot \mathrm{x} \frac{\mathrm{T}_{28}}{\mathrm{C}_{\mathrm{P}} \cdot \mathrm{n}_{27, \mathrm{~T}}}\right)
$$

(Levenspiel, 1999)

$\mathrm{C}_{\mathrm{P}}$ is calculable through the following equation:

$$
\mathrm{C}_{\mathrm{P}}=\mathrm{A}+\left(\mathrm{B} \cdot\left(\frac{\mathrm{T}_{28}}{1000}\right)\right)+\left(\mathrm{C} \cdot\left(\left(\frac{\mathrm{T}_{28}}{1000}\right)^{2}\right)\right)+\left(\mathrm{D} \cdot\left(\left(\frac{\mathrm{T}_{28}}{1000}\right)^{3}\right)\right)+\left(\mathrm{E} \cdot\left(\left(\frac{\mathrm{T}_{28}}{1000}\right)^{-2}\right)\right)
$$

Whereas the equation \& the factors A, B, C, D \& E are provided by NIST (NIST, 2021)

\subsubsection{Assuring Parameters}

Assuring parameters can be determined to provide more certainty to the suitability of the design, the first of which is space time. space time calculation is as such:

$$
\tau=\frac{\mathrm{V}_{\text {reactor }}}{\mathrm{V}_{27}}
$$

(Levenspiel, 1999)

Where $\mathrm{v}_{27}$ is such as:

$$
\mathrm{v}_{27}=\mathrm{n}_{27, \mathrm{~T}} \mathrm{RT}_{27} / \mathrm{P}_{27}
$$

(Levenspiel, 1999)

Space velocity on the other hand is by the following equation:

$$
\mathrm{s}=\frac{1}{\tau}
$$

\subsubsection{Determined Parameters}

Table three provides the main data for the design. 9 hours of work per day and tonnage fulfilled along with a suitable ammonia product fraction.

Table 5

\begin{tabular}{|l|l|r|}
\hline \multirow{2}{*}{ At 450 } & total mass & 85000 \\
\cline { 2 - 3 } & Work hours per day & 9.019576 \\
\cline { 2 - 3 } & NH3 mole fraction & 0.970476 \\
\hline
\end{tabular}

Table 6

\begin{tabular}{|l|r|}
\hline Wcat $(\mathrm{kg})$ & 1773.912042 \\
\hline Vcat $\left(\mathrm{m}^{\wedge} 3\right)$ & 0.806323656 \\
\hline Vreac $\left(\mathrm{m}^{\wedge} 3\right)$ & 1.46604301 \\
\hline
\end{tabular}

Table 7

\begin{tabular}{|l|r|}
\hline $\mathbf{D}$ & 1.465436776 \\
\hline $\mathbf{L}=\mathbf{2 . 5 D}$ & 3.663591939 \\
\hline
\end{tabular}


cognizancejournal.com

Ibrahim Mohamed Mahmoud Aboelkheir, Cognizance Journal of Multidisciplinary Studies, Vol.2, Issue.1, January 2022, pg. 10-37

(An Open Accessible, Multidisciplinary, Fully Refereed and Peer Reviewed Journal)

Table 8

\begin{tabular}{|l|r|r|r|r|l|}
\hline Kp & \multicolumn{1}{|l|}{ K1 } & k2 & \multicolumn{1}{l|}{ Rcat } & minus ra & $\begin{array}{l}\text { inverse } \\
\text { minus ra }\end{array}$ \\
\hline $7.62551 \mathrm{E}-05$ & 0.009248 & 121.2808 & 1.987 & 9.18119 & 0.108918 \\
\hline
\end{tabular}

Conversion is found at 0.063

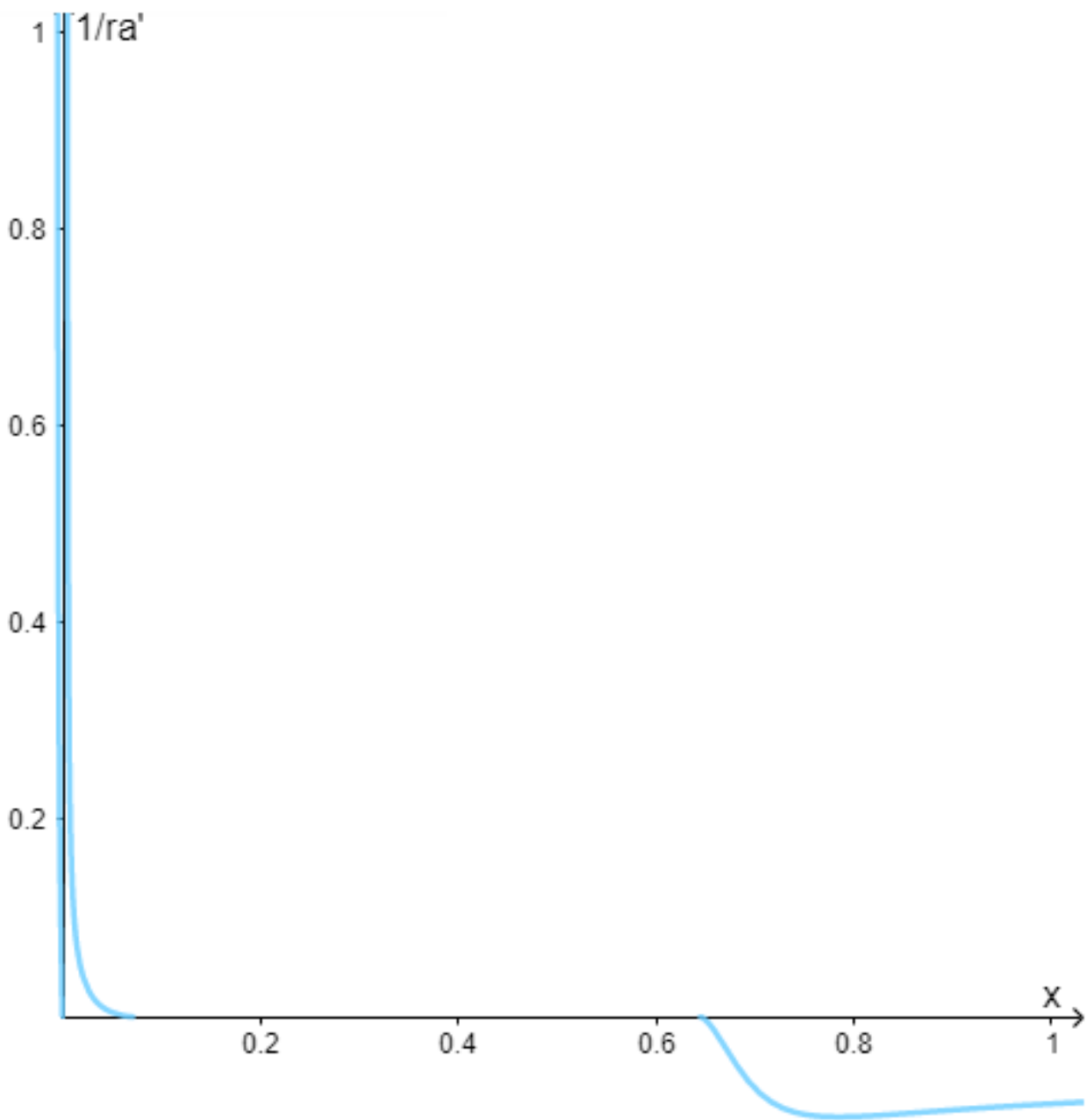

Figure 2

Table 9

\begin{tabular}{|c|c|c|c|c|c|c|}
\hline $\begin{array}{c}\text { particle } \\
\text { diameter }\end{array}$ & PdP/dZ & $\begin{array}{c}\text { pressure } \\
\text { difference (Pa) }\end{array}$ & Cp & slope & Po= & Tin \\
\hline 0.001 & $-1.1 \mathrm{E}+12$ & -276584.8604 & 49.03512647 & 0.000689 & 14772752.56 & 710.1541721 \\
\hline
\end{tabular}


cognizancejournal.com

Ibrahim Mohamed Mahmoud Aboelkheir, Cognizance Journal of Multidisciplinary Studies, Vol.2, Issue.1, January 2022, pg. 10-37

(An Open Accessible, Multidisciplinary, Fully Refereed and Peer Reviewed Journal)

ISSN: 0976-7797

Table 10

\begin{tabular}{|l|r|l|l|l|l|l|l|l|}
\hline $\begin{array}{l}\text { Reactor } \\
\text { Batch }\end{array}$ & 1st Conc. & $\begin{array}{l}\text { Fnl } \\
\text { Conc. }\end{array}$ & Conversion & time & $\begin{array}{l}\text { Space } \\
\text { Time } \\
\left(\mathbf{h}^{\wedge} \mathbf{- 1}\right)\end{array}$ & $\begin{array}{l}\text { Space } \\
\text { time }\left(\mathbf{s}^{\wedge} \mathbf{-} \text { - }\right. \\
\mathbf{1})\end{array}$ & $\begin{array}{l}\text { Space } \\
\text { Velocity } \\
(\mathbf{h})\end{array}$ & $\begin{array}{l}\text { Space } \\
\text { Velocity }(\mathbf{s})\end{array}$ \\
\hline N2 & 1.93391 & $\begin{array}{r}1.8104 \\
1\end{array}$ & 0.06386 & 865.35144 & 0.00274 & 9.865443 & 364.91011 & 0.10136 \\
\hline
\end{tabular}

Table 11

\begin{tabular}{|l|c|c|}
\hline \multicolumn{3}{|c|}{ Partial Pressure at 15 MP } \\
\hline Components & P27 & P28 \\
\hline CH4 & 760329.14 & 760329.14 \\
\hline H2S & 16.45 & 16.45 \\
\hline O2 & 26880.32 & 26880.32 \\
\hline N2 & 11627174.68 & 10884693.49 \\
\hline NH3 & 38857.40 & 1523819.77 \\
\hline H2O & 80235.04 & 80235.04 \\
\hline CO & 332.00 & 332.00 \\
\hline CO2 & 44640.00 & 44640.00 \\
\hline H2 & 2421534.98 & 194091.44 \\
\hline Total & 15000000.00 & 13515037.64 \\
\hline
\end{tabular}

\section{DISCUSSION}

The design is within range. Pressure drop is feasible. Size of the reactor is sensible, space time is suitable, along with all of the other parameters. Perhaps the next design shall be more efficient.

\subsubsection{The Second Chemical Engineering Design Per the Second Set of Parameters}

\subsection{Assumptions}

- The model is one-dimensional, with temperature and molar gradients varying only axially.

- For the system, the Temkin-Pyzhev reaction rate expression is valid (Murase et al., 1970; Morud and Skogestad, 1998; Froment et al., 2010).

- The compartments of the discretized reactor volume are well mixed.

- The system contains no heat or mass diffusion.

- Individual gases and gas mixtures exhibit ideal gas behavior.

- The activity of the catalyst is consistent throughout the reactor.

- The coefficient of heat transfer, the heat of reaction, and the heat capacities are constants. (Glemmestad, et al., 2018)

- The reactor's pressure is precisely controlled.

- $\quad$ The reactor arrives to steady state at $450{ }^{\circ} \mathrm{C}$

\subsection{Methodology}

The calculation steps for the second design are the same for the first design but for the determination of the Equilibrium constants.

The first constant, k1, follows the same equation.

$$
\mathrm{k}_{1}=\mathrm{k}_{0,1} \mathrm{e}^{-\frac{\mathrm{E}_{1}}{\mathrm{R}_{\mathrm{cat}} \mathrm{T}_{28}}}
$$

(Froment, et al., n.d.) (Levenspiel, 1999) 
$\mathrm{K}_{2}$, on the other hand, is determined solely by the Gillespie \& Beattie correlation:

$$
\mathrm{k}_{\mathrm{p}}=\frac{\mathrm{k}_{1}}{\mathrm{k}_{2}}
$$

(Gillespie \& Beattie, 1930)

This is detrimental to the design volume as will be discussed in the determined parameters segment.

$\mathrm{KP}$ is determined as:

$$
\mathrm{k}_{\mathrm{p}}=\mathrm{k}_{\mathrm{P}}^{\mathrm{GB}}{ }^{2}
$$

(Glemmestad, et al., 2018) (Gillespie \& Beattie, 1930)

Where,

$$
\mathrm{k}_{\mathrm{P}}^{\mathrm{GB}}=\mathrm{k}_{\mathrm{eq}} \cdot 10^{\gamma \cdot \frac{\mathrm{P}_{27}}{\mathrm{P}_{\text {atmosphere }}}}
$$

(Glemmestad, et al., 2018) (Gillespie \& Beattie, 1930)

The coefficient of pressure correction is given as,

$$
\gamma=\frac{0.1191849}{\mathrm{~T}_{\text {reactor }}}+\frac{91.87212}{\mathrm{~T}_{\text {reactor }}^{2}}+\frac{25122730}{\mathrm{~T}_{\text {reactor }}^{4}}
$$

(Glemmestad, et al., 2018) (Gillespie \& Beattie, 1930)

The newly calculated KP, is used, along with the extent of the reaction, to calculate the rates of equations, conversions \& flowrates necessary for the chemical \& mechanical engineering design.

\subsection{Determined Parameters}

Table 4 provides satisfactory results as the volumes and weights are consistent with the literature (Abbas \& G, 2015) (Choudhury, et al., 2020).

\section{Table 12}

\begin{tabular}{|c|c|}
\hline Wcat $(\mathrm{kg})$ & 1773.912042 \\
\hline Vcat $\left(\mathrm{m}^{\wedge} 3\right)$ & 0.806323656 \\
\hline vreac $\left(\mathrm{m}^{\wedge} 3\right)$ & 1.46604301 \\
\hline
\end{tabular}

This is where porosity chosen is 0.45 and the catalyst density is $2200 \mathrm{~kg} / \mathrm{m}^{\wedge} 3$. Different values were trialed and these were the most realistic, available in the market with optimizing lowering the volume of the reactor while maintaining pressure, temperature $\&$ extent of reaction.

Figure 3 provides a visualization to conversion stopping at 0.06 
cognizancejournal.com

Ibrahim Mohamed Mahmoud Aboelkheir, Cognizance Journal of Multidisciplinary Studies, Vol.2, Issue.1, January 2022, pg. 10-37

(An Open Accessible, Multidisciplinary, Fully Refereed and Peer Reviewed Journal)

ISSN: 0976-7797

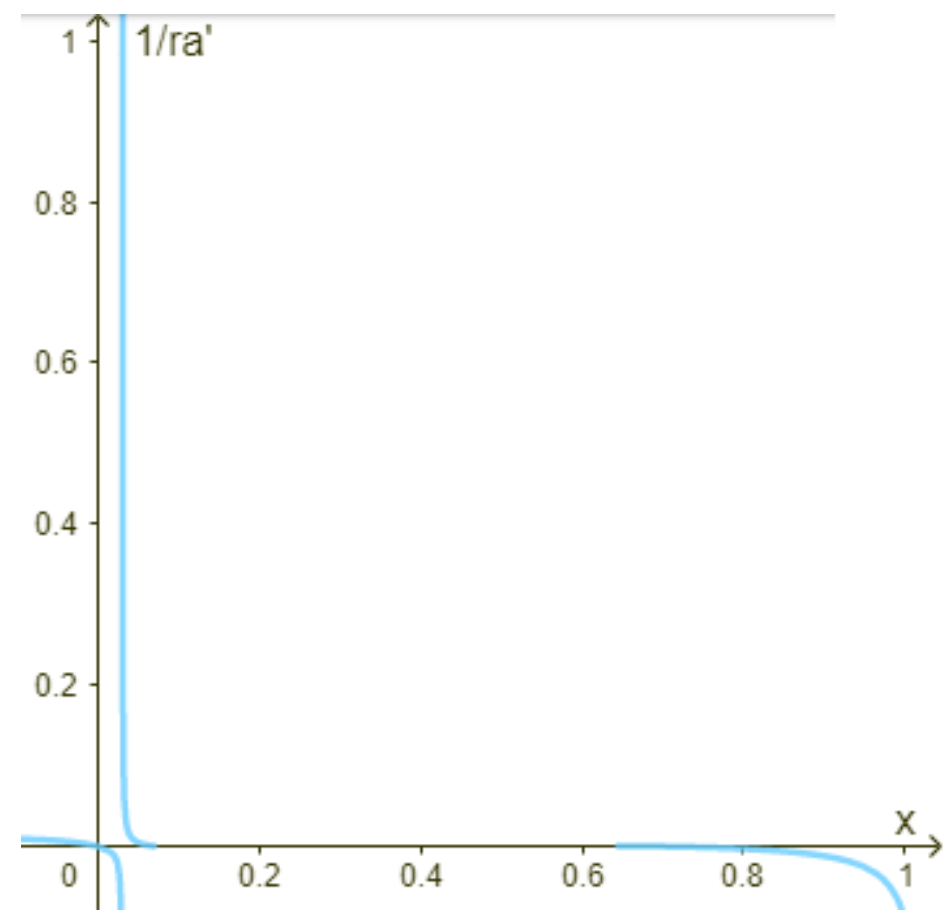

Figure 3

Table 13

\begin{tabular}{|l|l|}
\hline $\mathrm{D}$ & 0.907205 \\
\hline $\mathrm{L}=2.5 \mathrm{D}$ & 2.268014 \\
\hline
\end{tabular}

Table 14

\begin{tabular}{|c|c|c|c|c|c|c|}
\hline $\mathrm{PdP} / \mathrm{dZ}$ & Po & $\begin{array}{l}\text { particle } \\
\text { diameter }\end{array}$ & $\begin{array}{l}\text { Reactor } \\
\text { Area }\end{array}$ & $\begin{array}{l}\text { Mass } \\
\text { stream rate }\end{array}$ & $\begin{array}{l}\text { pressure } \\
\text { difference } \\
\text { (Pa) }\end{array}$ & $\begin{array}{l}\text { pressure } \\
\text { difference } \\
\text { (Bar) } \\
\end{array}$ \\
\hline $\begin{array}{l}- \\
1.12135 \mathrm{E}+1 \\
2\end{array}$ & 14829481.69 & 0.001 & 0.64639958 & 36.2033655 & -170518.31 & -0.1705183 \\
\hline
\end{tabular}

Table 15

\begin{tabular}{|c|c|c|c|c|c|}
\hline $\mathrm{Cp}$ & slope & Tout & $\mathbf{P o}=$ & vo = FaoRT/P & $\mathrm{t}=\mathrm{V} / \mathrm{vo}$ \\
\hline 49.73896 & 0.000699014 & 731.4988453 & 14768116.9 & 2329.797601 & 0.000629258 \\
\hline
\end{tabular}

Table 16

\begin{tabular}{|c|c|c|c|c|c|c|c|c|}
\hline $\begin{array}{c}\text { Reactor } \\
\text { Batch }\end{array}$ & 1st Conc. & $\begin{array}{c}\text { Fnl } \\
\text { Conc. }\end{array}$ & $\begin{array}{c}\text { Conversi } \\
\text { on }\end{array}$ & time & $\begin{array}{c}\text { Space } \\
\text { Time } \\
\left(\mathbf{h}^{\wedge} \mathbf{- 1}\right)\end{array}$ & $\begin{array}{c}\text { Space } \\
\text { time }\left(\mathbf{s}^{\wedge} \mathbf{-}\right. \\
\mathbf{1})\end{array}$ & $\begin{array}{c}\text { Space } \\
\text { Velocity } \\
(\mathbf{h})\end{array}$ & $\begin{array}{c}\text { Space } \\
\text { Velocity } \\
(\mathbf{s})\end{array}$ \\
\hline $\mathrm{N} 2$ & 1.87172 & 1.75221 & 0.06385 & 3.82613 & 0.00063 & 2.265327 \\
61 & $\begin{array}{c}1589.174 \\
11\end{array}$ & 0.44144 \\
\hline
\end{tabular}


The smaller dimensions of this vessel, but with the same output makes it the contender for the optimized reactor. All of the parameters provided have sensible values. Pressure drop is within safe levels, and the output temperature is not too high, although the 450 limit is went beyond, it is an advantage to the cost by reducing the volume of material needed for construction.

\subsubsection{RECOMMENDATIONS}

Revision to the pressure \& temperature constraints is recommended to reexamine the increasing of the maximum viable conversion rate. Modestly improving it may be, as multiple examinations were performed, the range between 450 \& 550 demonstrates promise. Comparison between these temperatures \& reactor volume is needed.

The heuristic relationship of the length of the reactor cylinder equaling two and half times the diameter of this cylinder is approximate. Other optimizing values are available in literature such as the length being two times the diameter (Levenspiel, 1999). Further analysis is recommended to determine varieties of reactor dimensions.

\section{CHAPTER 2}

\section{Mechanical Design of an Ammonia Reactor}

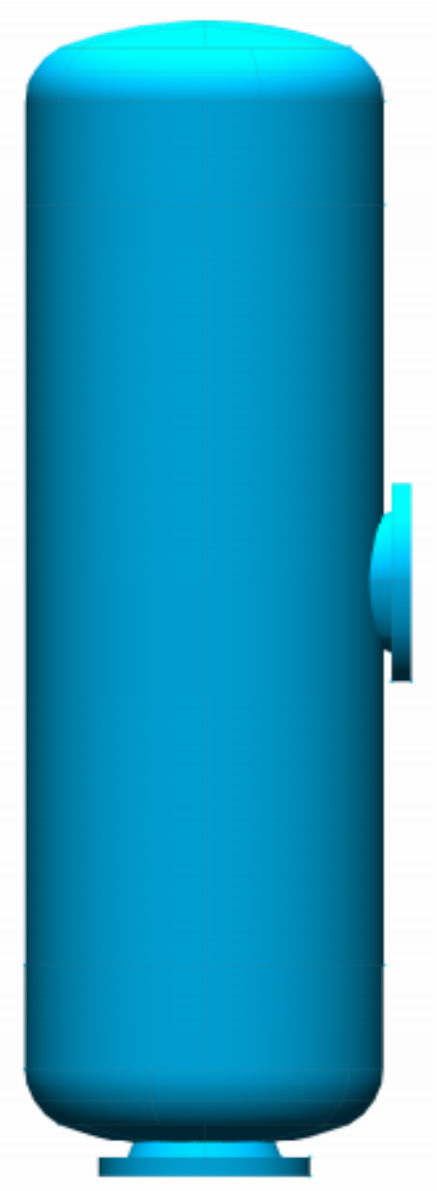

Figure 4, Plant 3D Diagram of the Designed R-5 Reactor

In Figure 4, Plant 3D Diagram of the Designed R-5 Reactor, a simple visualization of the reactor is provided. Section 4, Engineering Drawing of the Optimum Ammonia R-5 Reactor, offers detailed orthodiagrams of the reactor with equipment dimensions.

The Design's Framework

The plant is to be designed to operate for 330 days per year, with an annual maintenance shutdown. Process safety must be considered throughout the plant's design process. Environmental considerations must also be incorporated into the plant's design.

Services Offered 
On-site services include steam, cooling water, process water, electricity, compressed and instrument air. All byproducts must be appropriately treated prior to removal. (Patel, 2020)

Legal considerations. "materials, design considerations regarding the type of protocols that must be followed in order to demonstrate compliance with all applicable health and safety regulations."

\section{Section 1: Mechanical Design Methodology Outline}

\subsubsection{Plant Safety Considerations From the PaPer titled "Dynamic Model of an Ammonia SyntheSiS REACTOR BASED ON OPEN INFORMATION" (Glemmestad, et al., 2018)}

The cyclic material flow, of which is the Ammonia synthesis loop, is prone to depress the structural integrity of the pertinent plant items of the loop. This transpires by the temperature cyclic stress on the materials of the equipment. The item this paper is concerned with, the ammonia reactor, experiences an input temperature different than that of the output temperature.

The exothermic ammonia reaction necessitates that the reactants produce heat, by which the reactor temperature is set to rise. The constant flow of the input which has a lower temperature decreased the temperature of the reactor by mixing with the reactants in the reactor to arrive at the reaction equilibrium temperature. This results in that the throughput of the reactor exits with an output temperature that is equal to the equilibrium temperature.

"Dynamic Model of an Ammonia Synthesis Reactor based on Open Information" (Glemmestad, et al., 2018) provides temperature oscillation considerations that are integral for the mechanical safety considerations of the design. The model in this aforementioned study is of a $350{ }^{\circ} \mathrm{C}$ steady state ammonia reactor that experienced a sudden temperature drop of $120{ }^{\circ} \mathrm{C}$. Unsafe to any ill-equipped industrially designed reactor, temperature oscillatory behaviour of the reactor reached an amplitude of $320{ }^{\circ} \mathrm{C}$.

Considerable shifts in the temperature of a reactor result in an oscillatory behaviour. Two forms of this behaviour concern the safety aspects of the mechanical design of an ammonia reactor. The first, of which, is the slight alternation in temperature observed in the startup and shutdown of the reactor loop system. This variance is slight and depresses the structural integrity of the ammonia reactor on the long term (Niemantsverdriet \& Van Santen, 2013). Consideration of this phenomenon in the mechanical design of the reactor is of importance to the safety \& longevity of the reactor \& plant.

The second of the two portents is sudden shift in the temperature of a reactor. "Dynamic Model of an Ammonia Synthesis Reactor based on Open Information" (Glemmestad, et al., 2018) describes a fluctuation of a $120{ }^{\circ} \mathrm{C}$ drop in the temperature of a $350{ }^{\circ} \mathrm{C}$ ammonia reactor causing the reactor temperature to reach a high of $670{ }^{\circ} \mathrm{C}$ in oscillation.

Extending the thickness of the reactor walls at the design phase is sufficient to contain the risks caused by it. Thus, the cyclic stress \& oscillation are factored by 1.9 the effect of pressure on the vessel (Thomsen, 2000). Corrosion is added to the thickness by $2 \mathrm{~mm}$ and creep by $1 \mathrm{~mm}$ (Committee of Stainless Steel Producers, 1978) (Teel, 1980).

\subsubsection{THE MECHANICAL ENGINEERING DESIGN OF AN AMMONIA REACTOR IN THE PAPER TITLED "2500 MTPD OF AMMONIA FROM NAPHTHA"}

In this section, the piece of literature titled "2500 MTPD OF AMMONIA FROM NAPHTHA (Abbas \& G, 2015)" will be displayed and reviewed where relevant to the consequent chemical engineering design of an optimized ammonia reactor achieved in this paper.. This data is to be compared with the R-5 Reactor chemical engineering design.

\subsubsection{Catalytic Reactor}

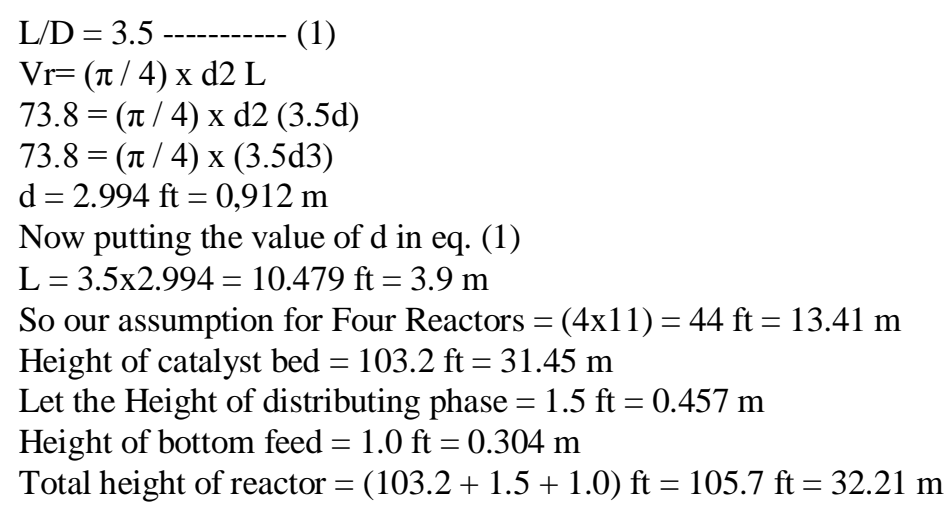

\subsubsection{REACTOR THICKNESS}

$\mathrm{W}=(\mathrm{Pi}) /(2 \mathrm{f}-\mathrm{Pi})$

By taking $50 \%$ above operating pressure $=1.15 \times 11=12.65 \mathrm{Kg} / \mathrm{cm} 3$ 
cognizancejournal.com

Ibrahim Mohamed Mahmoud Aboelkheir, Cognizance Journal of Multidisciplinary Studies, Vol.2, Issue.1, January 2022, pg. 10-37

(An Open Accessible, Multidisciplinary, Fully Refereed and Peer Reviewed Journal)

ISSN: 0976-7797

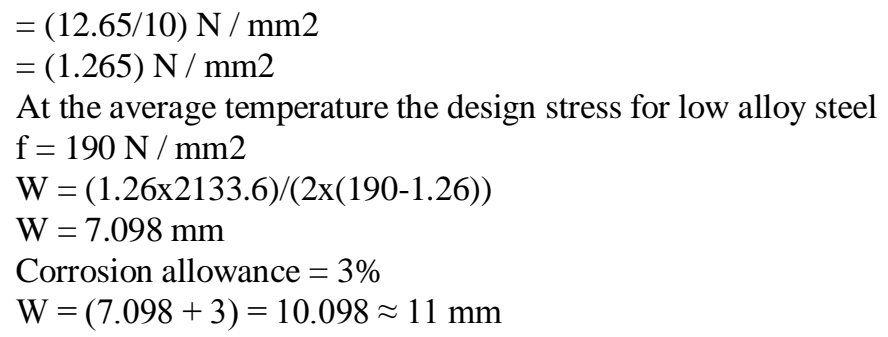

\subsubsection{SPECIFICATIONS OF REACTOR}

$\begin{array}{ll}\text { Diameter of reactor } & 2.994 \mathrm{ft}=0.9125 \mathrm{~m} \\ \text { Design pressure } & 370 \mathrm{psi}=25.17 \mathrm{~atm} \\ \text { Volume of catalyst } & 43.09 \mathrm{ft} 3=1.3 \mathrm{~m} 3 \\ \text { Volume of reactor } & 73.08 \mathrm{ft} 3=22.274 \mathrm{~m} 3 \\ \text { Height of catalyst bed } & 103 \mathrm{ft}=31.39 \mathrm{~m} \\ \text { Wall thickness } & 1.1 \mathrm{in}=0.0279 \mathrm{~m} \\ \text { Material of construction } & \mathrm{SST} \text { with } 8 \% \mathrm{Cr} \\ \text { Height of Reactor (4 beds) } & 106 \mathrm{ft}=32.30 \mathrm{~m}\end{array}$

\section{SECTION 2: LAWS \& REgulations}

If a vessel is designed and the stresses are surpassed, the vessel will fail, resulting in legal and ethical repercussions due to the loss of life and injury.

The main standards for the design of the reactor of this paper are the standards applied in Cyprus which are the EU standards.

Department of Labour Inspection reports that a directive 2014/29/EU on the harmonization of national legislation on simple pressure vessels.

The Regulations are published pursuant to Article 59 of the Essential Criteria for Certain Categories of Products to Comply with Laws. (Department of Labour Inspection, 2002)

ASME standards are also accepted in Cyprus. As such, they are used in this paper.

\section{SECTION 3: DESIGNS}

\subsubsection{Designs per the Parameters of the First Chemical Engineering Design}

\section{Assumptions}

The input pressure of the reactor is 150 bar as that is about an average within the limits of reactor pressure in the industry. It was chosen, moreover, as in initial value for the pressure as the material balance for the paper written on the ammonia plant as a whole (Abo Elkheir, et al., 2021) neared optimization at that value.

\section{Methodology}

The working pressure, Po, is first to be calculated:

\section{The Working Pressure}

$$
\mathrm{P}_{\mathrm{o}}=\mathrm{P}_{27} \cdot 110 \%
$$

$110 \%$ is chosen instead of $105 \%$ to increase safety, as it is commonly used by textbooks (Coulson, et al., 2005). The input pressure into R-5, P27, is chosen for the working pressure calculations as it is higher than the output pressure, P28.

Calculation of the parameters of a cylindrical vessel start with its wall thickness.

\section{Internal Pressure}

Internal Pressure, $\mathrm{Pi}$, is as:

$$
\mathrm{P}_{\mathrm{i}}\left(\frac{\mathrm{N}}{\mathrm{mm}^{2}}\right)=\frac{\mathrm{P}_{\mathrm{o}}}{10^{6}}(\mathrm{~Pa})
$$

(Coulson, et al., 2005) 


\section{Thickness of the Cylinder Wall}

For any design stress, $\mathrm{f}$, the thickness of the wall of the cylinder is such as:

$$
\mathrm{t}_{\text {cylinder wall }}(\mathrm{mm})=\left(\frac{\left(\mathrm{P}_{\mathrm{i}}\right)(1000 \mathrm{D})}{(2 \mathrm{f})-\left(\mathrm{P}_{\mathrm{i}}\right)}\right)
$$

(Coulson, et al., 2005)

By adding 2 as the chosen corrosion factor, 1 as the creep factor $\&$ inputting 1.9 as the cyclic stress $\&$ oscillation factor, the thickness accounting for design safety is determinable as:

$$
\mathrm{t}_{\text {cylinder wall }}(\mathrm{mm})=\left(\frac{\left(1.9 \mathrm{P}_{\mathrm{i}}\right)(1000 \mathrm{D})}{(2 \mathrm{f})-\left(1.9 \mathrm{P}_{\mathrm{i}}\right)}\right)+2+1
$$

\section{Cylinder Ends Thicknesses}

The first option is flat ends. It is not viable as the geometric properties of the shape don't allow for high pressures (Coulson, et al., 2005). Tables of thickness values are provided in the appendices, Calculations on the Ammonia Reactor Mechanical Design to elaborate on such point.

\section{Domed heads}

The second option is domed heads. They are the most expensive, but their withstanding to high pressures might deem them necessary.

The thickness of a domed head is determinable as:

$$
\mathrm{t}_{\text {domed head }}(\mathrm{mm})=\frac{7}{17} \mathrm{t} \text { cylinder wall }(\mathrm{mm})
$$

(Coulson, et al., 2005)

Safety thickness consideration of the domed head is determined by the same ratio multiplied by the safety considered thickness of a cylindrical wall.

\section{Ellipsoidal Heads}

According to Process Design by Northwestern University (Northwestern University, 2021), Ellipsoidal heads are more suitable for designs with a design pressure higher than 15 bar, while torispherical heads are more suitable for design pressures less than 15 bar. The design pressure of the R-5 reactor is 16.5 bar.

It is, thus, expectable that the ellipsoidal heads are the most optimum ends for being in the pressure range \& being cheaper than domed heads.

The thickness of an ellipsoidal head is calculable as:

$$
\mathrm{t}_{\text {ellipsoidal head }}(\mathrm{mm})=\left(\frac{\left(\mathrm{P}_{\mathrm{i}}\right)(1000 \mathrm{D})}{(2 \mathrm{fj})-\left(0.2 \mathrm{P}_{\mathrm{i}}\right)}\right)
$$

(Coulson, et al., 2005)

Where the chosen design stress for the construction material, $\mathrm{f}$, and the joint factor, $\mathrm{j}$, provide some degrees of freedom.

\section{Torispherical Heads}

The thickness of a torispherical head is defined as:

$$
t_{\text {torispherical head }}(\mathrm{mm})=\left(\frac{\left(\mathrm{P}_{\mathrm{i}}\right)\left(1000 \mathrm{R}_{\mathrm{c}}\right) \mathrm{C}_{\mathrm{s}}}{(2 \mathrm{fj})-\left(\left(\mathrm{C}_{\mathrm{s}}-0.2\right) \mathrm{P}_{\mathrm{i}}\right)}\right)
$$


Where,

$$
\mathrm{C}_{\mathrm{s}}=\left(\frac{1}{4}\right) *\left(3+\left(\sqrt{\frac{1}{0.09}}\right)\right)=1.583
$$

The former is computed from the latter:

$$
\mathrm{C}_{\mathrm{s}}=\left(\frac{1}{4}\right) *\left(3+\left(\sqrt{\frac{\mathrm{R}_{\mathrm{i}}}{\mathrm{R}_{\mathrm{c}}}}\right)\right)
$$

And,

$$
\mathrm{R}_{\mathrm{c}}=\mathrm{D}+\mathrm{t}_{\text {cylinder wall }}
$$

Results for Torispherical heads will be in the appendices, Calculations on the Ammonia Reactor Mechanical Design. However, calculations are rudimentary as all of the results fail. They are attached with the excel sheet. Likewise is for the flat ends.

\section{Determined Design No.1 Parameters}

Table 17

\begin{tabular}{|l|r|}
\hline \multicolumn{2}{|c|}{$\mathbf{L} / \mathbf{D}=\mathbf{2 . 5}$} \\
\hline $\mathbf{D}$ & 1.465 \\
\hline $\mathbf{L}$ & 3.663 \\
\hline
\end{tabular}

Table 18

\begin{tabular}{|c|l|}
\hline $\begin{array}{l}\text { Design } \\
\text { Pressure (Pa) }\end{array}$ & $\begin{array}{l}\text { internal } \\
\text { pressure }\end{array}$ \\
\hline 16500000.00 & \\
\hline
\end{tabular}

Table 19

\begin{tabular}{|c|c|c|c|c|c|c|}
\hline $\mathbf{P}$ & $\begin{array}{c}\text { pressure } \\
\text { difference }(\mathrm{Pa})\end{array}$ & Po & $\mathrm{PdP} / \mathrm{dZ}$ & $\begin{array}{c}\text { particle } \\
\text { diameter }\end{array}$ & Reactor Area & $\begin{array}{c}\text { Mass stream } \\
\text { rate }\end{array}$ \\
\hline 15000000 & -334983.79 & 14665016.21 & $-1.35622 \mathrm{E}+12$ & 0.001 & 1.686646087 & 36.2033655 \\
\hline
\end{tabular}

\begin{tabular}{|l|c|}
\hline Mass Density & 61.83673772 \\
Density of the stream 28 \\
kg/cum
\end{tabular}

Table 20

Table 21

\begin{tabular}{|l|r|r|r|}
\hline \multicolumn{1}{|c|}{ t alone } & \multicolumn{1}{|c|}{$450 \mathrm{C}$} & \multicolumn{2}{|c|}{ 500 C } \\
\hline Stainless steel 304 & 157.5225 & 147.888115 & 139.3643043 \\
\hline Stainless steel 316 & 131.7695 & 113.253896 \\
\hline Stainless steel 321 & 108.1866 & 74.74407047 \\
\hline Low alloy steel (Ni, Cr, Mo, V) & 66.51914 & & \\
\hline
\end{tabular}


cognizancejournal.com

Ibrahim Mohamed Mahmoud Aboelkheir, Cognizance Journal of Multidisciplinary Studies, Vol.2, Issue.1, January 2022, pg. 10-37

(An Open Accessible, Multidisciplinary, Fully Refereed and Peer Reviewed Journal)

Table 22

\begin{tabular}{|l|r|r|}
\hline $\mathbf{t}+\mathbf{t}$ of cycling stress + corrosion + creep & \multicolumn{1}{|c|}{$\mathbf{4 5 0} \mathbf{C}$} & \multicolumn{1}{c|}{$\mathbf{5 0 0} \mathbf{C}$} \\
\hline Stainless steel 304 & 334.3483 & 312.0578063 \\
\hline Stainless steel 316 & 275.407 & 292.5773269 \\
\hline Stainless steel 321 & 223.1842 & 234.2682754 \\
\hline Low alloy steel (Ni, Cr, Mo, V) & 134.7695 & 151.846405 \\
\hline
\end{tabular}

Table 23

\begin{tabular}{|c|c|c|}
\hline $\begin{array}{c}\text { t + t of cycling stress }+ \\
\text { corrosion + creep }\end{array}$ & $\mathbf{4 5 0} \mathbf{C}$ & $\mathbf{5 0 0 ~ C}$ \\
\hline Stainless steel 304 & 334.3483 & 312.0578063 \\
\hline Stainless steel 316 & 275.407 & 292.5773269 \\
\hline Stainless steel 321 & 223.1842 & 234.2682754 \\
\hline Low alloy steel (Ni, Cr, Mo, V) & 134.7695 & 151.846405 \\
\hline
\end{tabular}

Table 24

\begin{tabular}{|c|c|c|}
\hline $\begin{array}{c}\text { t + t of cycling stress }+ \\
\text { corrosion + creep }\end{array}$ & $\mathbf{4 5 0} \mathbf{C}$ & $\mathbf{5 0 0 ~ C}$ \\
\hline Stainless steel 304 & 137.6728 & 128.4943908 \\
\hline Stainless steel 316 & 113.4029 & 120.473017 \\
\hline Stainless steel 321 & 91.8994 & 96.46340753 \\
\hline Low alloy steel (Ni, Cr, Mo, V) & 55.49333 & 62.52499031 \\
\hline
\end{tabular}

Table 25

\begin{tabular}{|l|r|r|}
\hline $\begin{array}{l}\mathbf{t}+\mathbf{t} \text { of cycling stress }+ \\
\text { corrosion + creep }\end{array}$ & $\mathbf{4 5 0} \mathbf{C}$ & \multicolumn{1}{l|}{$\mathbf{~ C 0}$} \\
\hline Stainless steel 304 & 334.3483081 & 312.0578063 \\
\hline Stainless steel 316 & 275.407014 & 292.5773269 \\
\hline Stainless steel 321 & 223.1842459 & 234.2682754 \\
\hline Low alloy steel (Ni, Cr, Mo, V) & 134.7695193 & 151.846405 \\
\hline
\end{tabular}

Table 26

\begin{tabular}{|l|r|r|}
\hline $\begin{array}{l}\text { t + t of cycling stress + } \\
\text { corrosion + creep }\end{array}$ & $\mathbf{4 5 0}$ C & 500 C \\
\hline Stainless steel 304 & 306.4411041 & 287.1073068 \\
\hline Stainless steel 316 & 254.9954483 & 270.0896483 \\
\hline Stainless steel 321 & 208.5336541 & 218.4652856 \\
\hline Low alloy steel (Ni, Cr, Mo, V) & 127.9205987 & 143.6860101 \\
\hline
\end{tabular}




\subsubsection{Designs per the Parameters of the Second Chemical Engineering Design}

The Assumptions \& Methodology for the second mechanical design are the same as those of the first Mechanical Design.

\section{Determined Design No.2 Parameters}

In table 25, the winning material for the cylinder thickness is Low Alloy steel at 450 Celsius, as only it fits thin vessel definition, of which is a constraint for the mechanical design.

Table 27

\begin{tabular}{|l|r|r|}
\hline $\begin{array}{l}\text { t }+ \text { t of cycling stress + corrosion } \\
\text { +creep }\end{array}$ & $\mathbf{4 5 0} \mathbf{C}$ & \multicolumn{1}{l|}{ 500 C } \\
\hline Stainless steel 304 & 208.12 & 194.32 \\
\hline Stainless steel 316 & 171.63 & 182.26 \\
\hline Stainless steel 321 & 139.30 & 146.17 \\
\hline Low alloy steel (Ni, Cr, Mo, V) & 84.57 & 95.14 \\
\hline
\end{tabular}

Ellipsoidal heads are cheaper than hemispherical heads and provide less internal volume, they are the same thickness as the shell, and are most common for systems with greater than 15 bar. Torispherical heads are the cheapest of the three options and are most commonly used when pressures do not exceed 15 bar.

The chosen thickness for the chosen design of the ellipsoidal head can be seen below in Table 26. It is 87

Table 28

\begin{tabular}{|l|r|l|}
\hline $\begin{array}{l}\text { t }+\mathbf{t} \text { of cycling stress }+ \\
\text { corrosion + creep }\end{array}$ & $\mathbf{4 5 0}$ C & 500 C \\
\hline Stainless steel 304 & 196.8314591 & 185.629487 \\
\hline Stainless steel 316 & 166.7074195 & 175.651551 \\
\hline Stainless steel 321 & 138.6071615 & 144.687291 \\
\hline Low alloy steel (Ni, Cr, Mo, V) & 87.71357933 & 97.8883662 \\
\hline
\end{tabular}

It satisfies thin vessel $1 / 10$ ratio.

\section{SECTION 4: SELECTED OPTIMIZED DESIGN OF THE R-5 REACTOR}

\subsubsection{Further Methodology}

\section{Weight force on the vessel $(k N)$}

The Weight force acting on a vessel is determined by the following:

$$
\mathrm{W}_{\mathrm{v}}=240 \cdot \mathrm{C}_{\mathrm{v}}\left(\mathrm{D}+\left(\frac{\mathrm{t}_{\text {cylinder wall }}}{1000}\right)\right)\left(\mathrm{L}+\left(0.8\left(\mathrm{D}+\left(\frac{\mathrm{t}_{\text {cylinder wall }}}{1000}\right)\right)\right)\right)\left(\left(\frac{\mathrm{t}_{\text {cylinder wall }}}{1000}\right)\right)
$$

(Coulson, et al., 2005)

Where $\mathrm{Cv}$ is equal to 1.08 as the streams are gaseous.

$$
\mathrm{W}_{\mathrm{v}}=240 \cdot 1.08\left(\mathrm{D}+\left(\frac{\mathrm{t}_{\text {cylinder wall }}}{1000}\right)\right)\left(\mathrm{L}+\left(0.8\left(\mathrm{D}+\left(\frac{\mathrm{t}_{\text {cylinder wall }}}{1000}\right)\right)\right)\right)\left(\left(\frac{\mathrm{t}_{\text {cylinder wall }}}{1000}\right)\right)
$$

(Coulson, et al., 2005)

\section{Reactor Weight $(k N)$}

The weight the reactor loads is equal to:

$$
\mathrm{W}_{\text {weight, reactor }}=\mathrm{W}_{\text {reactor }} \cdot \frac{9.8}{1000}
$$

(Coulson, et al., 2005) 


\section{Platform Weight $(k N)$}

The weight of the platform is:

$$
\mathrm{W}_{\text {platform }}=1.7\left(\pi \frac{\mathrm{D}}{4}\right)
$$

(Coulson, et al., 2005)

Plain Ladder Weight $(k N)$

$$
\mathrm{W}_{\text {plain ladder }}=150 \frac{\mathrm{L}}{1000}
$$

(Coulson, et al., 2005)

Weight of insulation $2 x$ to allow for fittings $(K N)$

$$
\mathrm{W}_{\text {insulation, } 2 \mathrm{x}}=9.8 \mathrm{~V}_{\text {insulation }} \rho_{\text {mineral wood }} \frac{2}{1000}
$$

(Coulson, et al., 2005)

Density of mineral wood, $\rho_{\text {mineral wood }}$, is equal to 130 (Coulson, et al., 2005).

While the volume of insulation, $\mathrm{V}_{\text {insulation }}$ is equal to:

$$
\mathrm{V}_{\text {insulation }}=2 \pi \mathrm{D}_{\text {insulation }} \frac{\mathrm{L}}{1000}
$$

(Coulson, et al., 2005)

Where, Dinsulation, is $100 \mathrm{~mm}$ (Choudhury, et al., 2020).

\section{Deadweight (kN)}

Deadweight is the sum of all of the former.

\section{The loading per unit length of the column (N/m)}

$$
\mathrm{F}_{\mathrm{W}}=\mathrm{P}_{\mathrm{W}} \mathrm{D}_{\mathrm{ff}}
$$

(Coulson, et al., 2005)

$$
\mathrm{P}_{\mathrm{W}}=0.07 *\left(\mathrm{v}_{\mathrm{W}}^{2}\right)
$$

(Coulson, et al., 2005)

$$
\mathrm{v}_{\mathrm{W}}=70\left(\frac{\mathrm{m}}{\mathrm{s}}\right)
$$

(Gökçekuş, et al., 2019)

Bending Moment (Nm)

$$
\mathrm{M}_{\mathrm{x}}=\mathrm{F}_{\mathrm{W}} \frac{(\mathrm{L})^{2}}{2}
$$

(Coulson, et al., 2005)

The second moment of area of the vessel about the plane of bending $\left(\mathrm{mm}^{\wedge} 4\right)$

$$
\mathrm{I}_{\mathrm{v}}=\pi \frac{\left(\left(\mathrm{D}_{\mathrm{o}}\right)^{4}\right)-\left((\mathrm{D})^{4}\right)}{64}
$$

(Coulson, et al., 2005) 
Bending Stress (N/mm^2)

$$
\sigma_{\mathrm{b}}= \pm 1000 \mathrm{M}_{\mathrm{x}} \frac{\left(\mathrm{D} \frac{1000}{2}\right)+\mathrm{t}_{\text {cylinder }}}{\mathrm{I}_{\mathrm{v}}}
$$

(Coulson, et al., 2005)

Total Deadweight Stress $\left(\mathrm{N} / \mathrm{mm}^{\wedge} 2\right)$

$$
\sigma_{\mathrm{W}}=\frac{1000 \mathrm{~W}_{\text {weight, reactor }}}{\pi\left(\mathrm{D}_{\mathrm{o}}\right) \mathrm{t}_{\text {cylinder }}}
$$

(Coulson, et al., 2005)

Hoop (Circumferential) Stress $\left(\mathrm{N} / \mathrm{mm}^{\wedge} 2\right)$

$$
\sigma_{\mathrm{h}}=\frac{1000 \mathrm{P}_{\mathrm{i}} \mathrm{D}_{\mathrm{i}}}{2 \mathrm{t}_{\text {cylinder }}}
$$

(Coulson, et al., 2005)

\section{Longitudinal Stress $\left(\mathrm{N} / \mathrm{mm}^{\wedge} 2\right)$}

$$
\sigma_{\mathrm{L}}=\frac{1000 \mathrm{P}_{\mathrm{i}} \mathrm{D}_{\mathrm{i}}}{4 \mathrm{t}_{\text {cylinder }}}
$$

(Coulson, et al., 2005)

Upwind Stress $\left(\mathrm{N} / \mathrm{mm}^{\wedge} 2\right)$

$$
\sigma_{\mathrm{z}}=\sigma_{\mathrm{L}}-\sigma_{\mathrm{W}}+\sigma_{\mathrm{b}}
$$

(Coulson, et al., 2005)

\section{Downwind Stress (N/mm^2)}

$$
\sigma_{\mathrm{z}}=\sigma_{\mathrm{L}}-\sigma_{\mathrm{W}}-\sigma_{\mathrm{b}}
$$

(Coulson, et al., 2005)

Critical Buckling Stress (N/mm^2)

$$
\sigma_{\mathrm{c}}=2 *\left(10^{4}\right) *\left(\frac{\mathrm{t}_{\text {cylinder }}}{\mathrm{D}_{\mathrm{o}}}\right)
$$

(Coulson, et al., 2005)

The Maximum Compressive Stress (N/mm^2)

$$
=\sigma_{\mathrm{b}}+\sigma_{\mathrm{W}}
$$

(Coulson, et al., 2005)

The greatest difference between the principal stresses on the down-wind side $\left(\mathrm{N} / \mathrm{mm}^{\wedge} 2\right)$

$$
=\sigma_{\mathrm{h}}-\sigma_{\mathrm{z}}
$$

(Coulson, et al., 2005) 
Radial Stress

$$
=\frac{P_{i}}{2}
$$

(Coulson, et al., 2005)

Inlet, Outlet Pipes \& Flange Design

Nozzle Inlet Optimum Diameter (mm)

$$
\mathrm{d}_{\text {in }}=260\left(\mathrm{G}^{0.52}\right) /\left(\rho_{27}^{0.37}\right)
$$

Where $\mathrm{G}$ is the mass estimated mass streams, and $\rho$ is the density of a stream also estimated using studies (Abbas \& $\mathrm{G}, 2015$ ) (Choudhury, et al., 2020) \& confirmed using Aspen simulation.

Nozzle Outlet Optimum Diameter (mm)

$$
\mathrm{d}_{\text {out }}=260\left(\mathrm{G}^{0.52}\right) /\left(\rho_{28}^{0.37}\right)
$$

Nozzel Inlet Thickness (mm)

$$
t_{\text {inlet, nozzle }}=10 P_{i} \frac{d_{\text {in }}}{(20 f)+\left(10 P_{i}\right)}
$$

Nozzel Outlet Thickness (mm)

$$
t_{\text {outlet, nozzle }}=10 P_{i} \frac{d_{\text {out }}}{(20 f)+\left(10 P_{i}\right)}
$$

2.4.2.

Parameters

Table 29

\begin{tabular}{|c|c|}
\hline $\begin{array}{c}\text { End } \\
\text { Thickness }\end{array}$ & wall thickness \\
\hline 87.44507 & 85.57432953 \\
\hline
\end{tabular}

$\mathrm{t}$ ellipsoidal double welded spot $=\mathrm{t}+\mathrm{t}$ of cycling stress + corrosion + creep

Table 30

\begin{tabular}{|l|r|}
\hline dff (effective diameter) & 1.351354081 \\
\hline The loading per unit length of the column (N/m) & 463.5144499 \\
\hline $\begin{array}{l}\text { Iv the second moment of area of the vessel about the } \\
\text { plane of bending. (mm^4) }\end{array}$ & 14243075040 \\
\hline
\end{tabular}

Table 31

\begin{tabular}{|l|r|}
\hline Weight force on the vessel $(\mathbf{k N})$ & 66.88749193 \\
\hline Reactor Weight $(\mathbf{k N})$ & 17.38433801 \\
\hline Platform Weight $(\mathbf{k N})$ & 1.211279703 \\
\hline Plain Ladder Weight $(\mathbf{k N})$ & 0.340202033 \\
\hline $\begin{array}{l}\text { Weight of insulation 2x to allow for } \\
\text { fittings(KN) }\end{array}$ & 3.63098904 \\
\hline Deadweight (kN) & 89.45430073 \\
\hline
\end{tabular}


Table 32

\begin{tabular}{|l|r|}
\hline Bending Stress (N/mm^2) & +-0.019860964 \\
\hline Total Deadweight Stress (N/mm^2) & 2.944992298 \\
\hline Hoop (Circumferential) Stress (N/mm^2) & 88.49546637 \\
\hline Longitudinal Stress (N/mm^2) & 44.24773318 \\
\hline Upwind Stress (N/mm^2) & 41.32260185 \\
\hline Downwind Stress (N/mm^2) & 41.28287992 \\
\hline Critical Buckling Stress (N/mm^2) & 1705.506275 \\
\hline The Maximum Compressive Stress (N/mm^2) & 2.964853263 \\
\hline $\begin{array}{l}\text { he greatest difference between the principal stresses will be } \\
\text { on the down-wind side(N/mm^2) }\end{array}$ & 129.7783463 \\
\hline Radial Stress & 8.25 \\
\hline
\end{tabular}

Table 33

\begin{tabular}{|l|l|}
\hline Nozzel Inlet Optimum Diameter (mm) & 380.8556 \\
\hline Nozzel Outlet Optimum Diameter (mm) & 365.3942 \\
\hline
\end{tabular}

Table 34

\begin{tabular}{|l|l|}
\hline Nozzel Inlet Thickness (mm) & 17.62726 \\
\hline Nozzel Outlet Thickness (mm) & 16.91165 \\
\hline
\end{tabular}

\section{Discussion}

The operating pressure was considered as Pi as it is higher than Po, such that when the design pressure is calculated, it accounts for the highest pressure along the length of the reactor.

The design pressure was calculated as $10 \%$ higher than the operating pressure.

The cylindrical shape of the vessel was chosen as the pressure is not as high to deem the expensive spherical vessel cost efficient.

This shape of the ends of the vessel was chosen to be ellipsoidal in this list instead of the others due to it being cheaper and more efficient.

- Cylinder

- Sphere

- Conné

- Ellipsoid

- Torus

The argument for the Hemispherical ends to be the optimum is the choice for extra safety as the maximum for torispherical heads 150 bar is the reaction pressure, and hemispherical heads can take so. Also, freedom is given for the plant to have a wider range of pressure over 150/200 bar as to leave the choice of pressure to them in the plant rather than limit the pressure limit to the design.

The vessel thickness can be examined as a constant and higher temperatures can be operated at the expense of the cycling $\&$ oscillation temperature coefficient. 
Mixing vessel components of different materials is a bad idea in design as it restricts liberty in plant operation to change the parameters as each material is susceptible to its own chemical and physical vulnerabilities.

The chosen base is a skirt and the reactor is within a platform

a) caged ladders, steel, $360 \mathrm{~N} / \mathrm{m}$ length,

b) plain ladders, steel, $150 \mathrm{~N} / \mathrm{m}$ length,

c) platforms, steel, for vertical columns, $1.7 \mathrm{kN} / \mathrm{m} 2$ area,

(Coulson, et al., 2005)

Plain Ladder is chosen for less weight and steel platform is chosen.

The primary sources of dead weight loads are as follows:

1. The vessel shell.

2. The vessel's fittings, including manways and nozzles.

3. Internal fittings: plates (along with the fluid contained within the plates); heating and cooling coils.

4. Fittings for the exterior: ladders, platforms, and piping.

5. Non-self-contained auxiliary equipment; condensers, agitators.

6. Insulation. Coulson and Richardson (Coulson, et al., 2005)

$100 \mathrm{~mm}$ was chosen as to follow optimum design standards.

When the vessel is not under pressure, the maximum compressive stress occurs.= significantly less than the critical buckling stress. (Coulson, et al., 2005)

The maximum compressive stress in a vessel wall must not exceed the value specified in equation 13.74; or the material's maximum allowable design stress, whichever is lower. (Coulson, et al., 2005) 


\subsubsection{Engineering Drawing of the Optimum Ammonia R-5 Reactor}

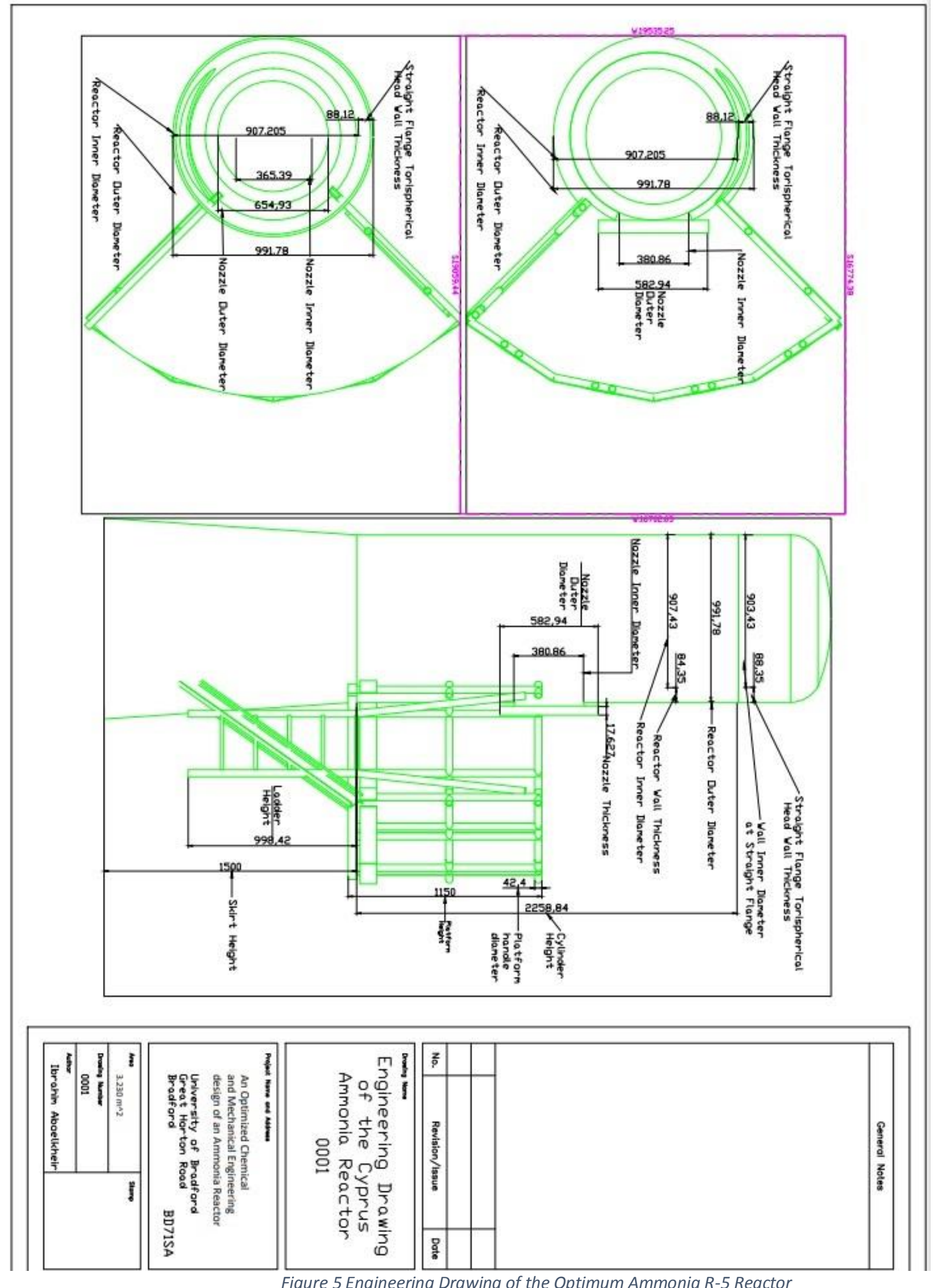

Figure 5 Engineering Drawing of the Optimum Ammonia R-5 Reactor 

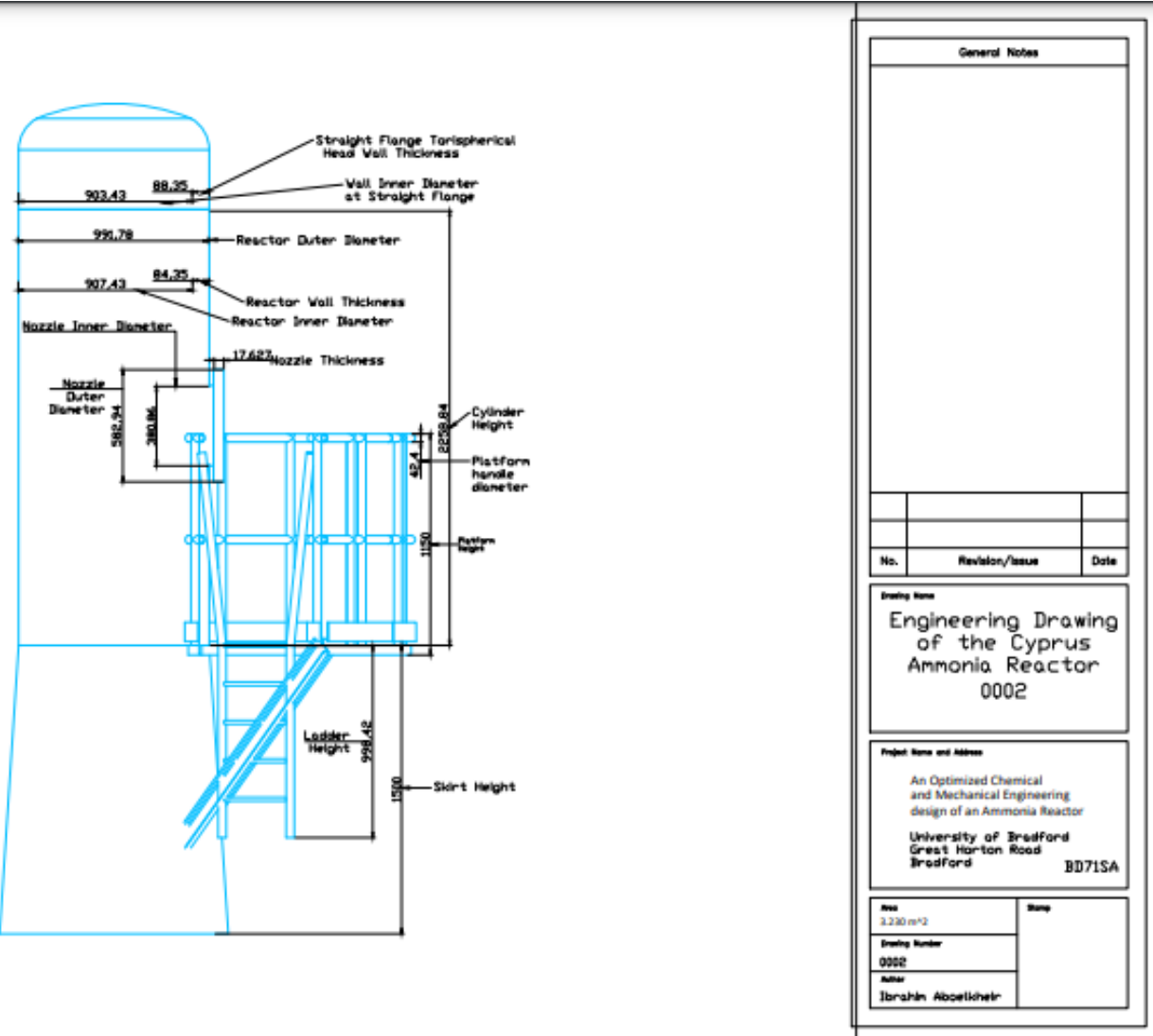

Figure 6 Orthodiagram front view
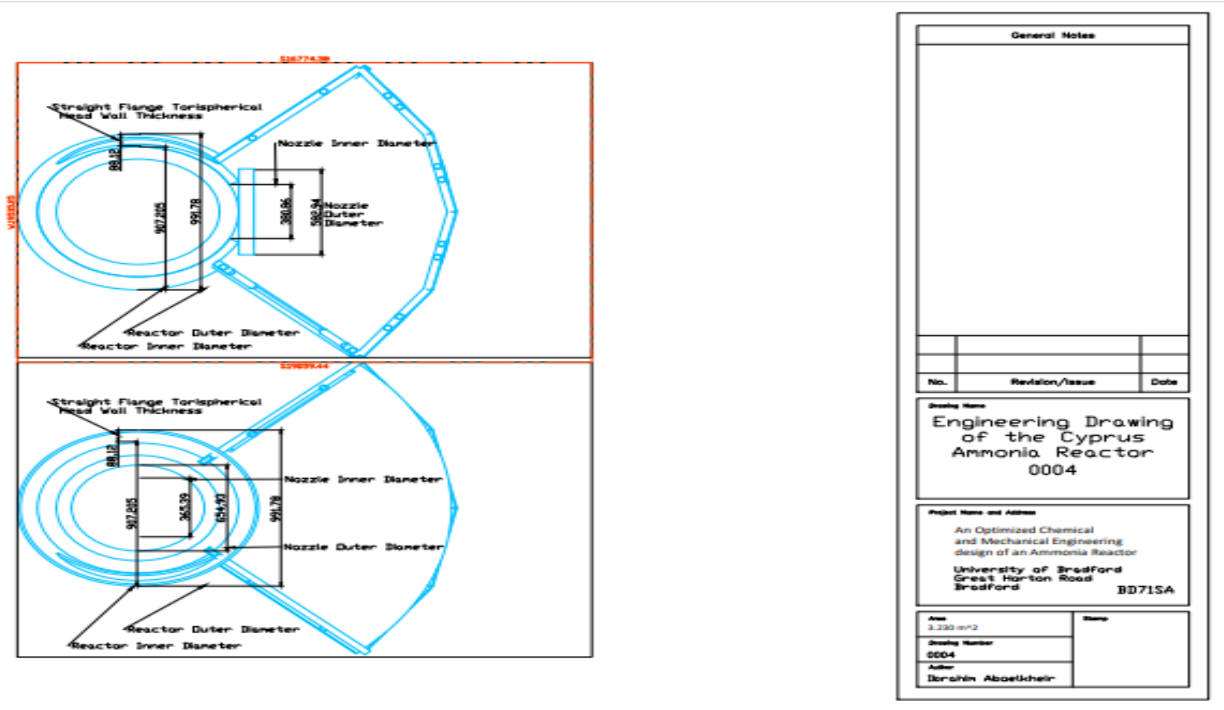

Figure 7 Orthodiagram Top and bottom views 


\subsubsection{Recommendations}

Although ASME is accepted in Cyprus (Tuev Nord, 2021), the main accepted Standard is the European standard (Department of Labour Inspection, 2002). As such, it is on page 5 of BS EN 13445-3:2021 that Cyprus accepts the standard. It is, thus, recommended that the redesigns of the American standardized, optimized design are approximated or recalculated into the European \& British standards as to allow flexibility \& accuracy in the communication between the engineers working on the construction of this design with the firms, contractors, \& sellers or manufacturers of the equipment.

The entry point of the input was chosen as the midpoint of the cylinder in the orthodiagrams \& diagrams, and the output was set in the bottom. This is contradictory to the recommendations made by the book titled, Chemical Engineering Design (Coulson, et al., 2005), as the gas flows upwards. Recommendation is at hand that the redesigns of the equipment correct this erroneous representation of the otherwise, well-calculated chemical \& mechanical design of the R-5 reactor.

\section{Conclusion}

The chemical and mechanical designs were finalized satisfying the safety standards of ASME. Flanges, Pipes and cylinders were all fixed to available specifications. The optimized design succeeded at lowering the reactor volume and keeping the output and conversion. Thus, the mechanical equipments are cheaper to construct.

\section{References}

[1]. Abbas, M. T. \& G, S., 2015. 2500 MTPD OF AMMONIA FROM NAPHTHA, Multan: institute of Engineering Technology of The National Fertilizer Corporation.

[2]. Abo Elkheir, I. et al., 2021. Liquid Ammonium Plant, Bradford: Univesity of Bradford.

[3]. Choudhury, S., Hemal, N. R., Mazumder, A. A. \& Suhan, B. K., 2020. Optimal design of ammonia synthesis reactor for a process industry. s.l.:Journal of King Saud University - Engineering Sciences.

[4]. Committee of Stainless Steel Producers, 1978. Stainless Steels in Ammonia Production. Washington D.C.: American Iron \& Steel Institute.

[5]. Coulson, J., Richardson, J. \& Sinnott, R. K., 2005. Chemical engineering design. 4 ed. Oxford: Elsevier ButterworthHeinemann.

[6]. Department of Labour Inspection, 2002. Essential Requirements that Certain Categories of Products should fulfill Laws, Nicosia: Department of Labour Inspection.

[7]. Froment, G. F., Bischoff, K. B. \& Wilde, J. D., n.d. Chemical Reactor Analysis and Design. 2nd ed. s.l.:John Wiley \& Sons,.

[8]. Gillespie, L. J. \& Beattie, J. A., 1930. The Thermodynamic Treatment of Chemical Equilibria in Systems Composed of Real Gases. I. An Approximate Equation for the Mass Action Function Applied to the Existing Data on the Haber Equilibrium. PHYSICAL REVIEW, Volume 36, p. 743.

[9]. Glemmestad, B., Jinasena, A. \& Lie, B., 2018. Dynamic Model of an Ammonia Synthesis Reactor based on Open Information. Linköping, Linköpings Universitet.

[10].Gökçekuş, H., Al Zoubi, R. \& Kassem, Y., 2019. The Possibility of Generating Electricity Using Small-Scale Wind Turbines and Solar Photovoltaic Systems for Households in Northern Cyprus: A Comparative Study. Environments, 4(6), p. 47.

[11].Levenspiel, O., 1999. Chemical Reaction Engineering. Hoboken, NJ: Wiley.

[12].Morud, J. C. \& Skogestad, S., n.d. Analysis of instability in an industrial ammonia reactor. AIChE Journal, 4(44), pp. 888-895.

[13].Murase, A., Roberts, H. L. \& Converse, A. O., 1970. Optimal Thermal Design of an Autothermal Ammonia Synthesis Reactor. Industrial \& Engineering Chemistry Process Design and Development, 4(9), p. 503-513.

[14].Niemantsverdriet, J. W. \& Van Santen, R. A., 2013. Chemical kinetics and catalysis. s.l.:Springer-Verlag New York.

[15].NIST, 2021. Ammonia. [Online] Available at: https://webbook.nist.gov/cgi/cbook.cgi?Name=Ammonia\&Units=SI [Accessed 1 February 2021].

[16].Northwestern University, 2021. Process Design. s.1.:Northwestern University.

[17].Patel, R., 2020. Final Year Design Project (2020-21), Bradford: University of Bradford.

[18].Rosen, A., 2014. Reactor Design. s.l.:Northwestern University. 
[19].Teel, R. B., 1980. The Stress Corrosion Craking of Steels in Ammonia - a Survey, Argonne: Argonne National Laboratory.

[20]. Thomsen, S. G., 2000. Impact of Catalyst Forces on the Ammonia Converter Internals, Lyngby: Haldor Topsoe.

[21].Tuev Nord, 2021. ASME Worldwide. [Online] Available at: https://www.tuev-nord.de/en/asme/asme-code/asmeworldwide/ [Accessed 25 July 2021]. 